\title{
Manuseio anestésico \\ de paciente com gastrosquise
}

\author{
CET-SBA, Hospital Universitário Antônio Pedro da Universidade Federal \\ Fluminense, Niterói, Rio de Janeiro
}

- Elizabeth Femandes Voz

- Marco A. C. Resende

- Alberto Panha

- Ewatd Garrido

- Leonardo C. M. Miranda
INTRロDUÇÃ̃

A gastrosquise é um defeito congênito da parede abdominal anterior, que permite a herniação das vísceras abdominais, usualmente do lado direito, sem a cobertura do saco herniário. Raramente é associada a outras anomalias congênitas. Cuidados no controle hidroeletrolítico, glicêmico e ventilatório devem ser tomados.

RELATD DO CASD

RN do sexo feminino, $2,775 \mathrm{~kg}, 60 \mathrm{~cm}, 6$ horas de vida, após gestação de 40 semanas, P3 (antigo ASA III), nascido de parto cesário, sem intercorrências logo após o nascimento. Na sala de operação foram usadas compressas umedecidas, com solução de cloreto de sódio $0,9 \%$ aquecida para proteger as vísceras expostas. O RN foi mantido sobre colchão térmico. Drenou-se o conteúdo gástrico e foram realizadas venóclises com jelco nos 22 e 24 em membros superiores esquerdo e direito, respectivamente. Monitarização feita com oxímetro de pulso/cardioscópio, ECG, em DII e V5, pressão arterial não-invasiva e estetoscópio precordial. Pré-oxigenação por 5 minutos. Intubado acordado. Utilizado sevoflurano em $\mathrm{O}_{2}(1 / \mathrm{min})$ para a manutenção, em sistema sem absorvedor de $\mathrm{CO}_{2}$. Ventilação controlada. Relaxamento muscular com cisatracúrio (dose total de $0,6 \mathrm{mg}$ ). Volume total infundido de $250 \mathrm{ml}$ (solução de glicose a $5 \%$ e Ringer com lactato) e diurese total de $5 \mathrm{ml}$. O procedimento cirúrgico durou 120 minutos, sem intercorrências.
DISCUSSÃa

A doença em questão acarreta grande déficit de fluidos e eletrólitos, com necessidade de reposição agressiva e monitorização do débito urinário. Pode ocorrer hipoglicemia grave, de rebote, durante a reposição. As dificuldades no perioperatório, em conseqüência do aumento da pressão intra-abdominal e da compressão da veia cava inferior, podem tornar a ventilação inadequada, prejudicar o fluxo sanguíneo visceral e levar a íleo prolongado, além de diminuir o clearance hepático e renal.

REFERÊNCIAS

Friedhoff RJ. Other neonatal emergencies. In: Faust A, editor. Anesth. review. 3rd ed. Philadelphia: Churchill, Uvingstone; 2002.p.411-2.

2 Barash PG. et al. Anestesia clínica. São Paulo: Manole, $4^{a}$ ed.p.1185-7.

3. Tan, KH et al Congenital anterior adominal wall deffects in England and Wales 1987 - 93: retrospective análisis of OPCS data. BMJ 1996; 313:903-6.

4. Vilela PC, et al. Fatores prognósticos para óbito em recém-nascidos com gastrosquise.Acta Cir. Bras. 2002;17(Suppl.1):17-20.

5. Werler WW, et al. Maternal medication use and risks of gastroschisis and small intestinal atresia. Am J Epitemiol. 2002;155(1):26-31

\section{Endereço para correspondência}

Marco A. C. Resende

Rua General Pereira da Silva, 208 - apto. 1.002 - Icaraí

Niterói (R) - CEP 24220-031

Tel. 1+55 21) 2711-2690 / 9952-2721

E-mail: macresende@ig.com.br 